Original Research Paper

\title{
The Deproteinization, Antioxidant Acticities and Inhibitory Effect on $\alpha$-Amylase of Polysaccharides from Corn Silk
}

\author{
Yaping Li, Songbiao Shi, Xiudong Yang and Hongli Zhou \\ School of Chemistry and Pharmaceutical Engineering, Jilin Institute of Chemical Technology, Jilin 132022, PR China
}

Article history

Received: 29-12-2018

Revised: 02-02-2019

Accepted: 23-05-2019

Corresponding Author: Hongli Zhou

School of Chemistry and Pharmaceutical Engineering, Jilin Institute of Chemical Technology, Jilin 132022, PR China

Email: zhouhongli@jlict.edu.cn

\begin{abstract}
An approach of deproteinization of polysaccharides from corn silk (CSPs) was established to improve the purity and activities of CSPs by investigating Sevag method, trichloroacetic acid (TCA) method and $\mathrm{HCl}$ method. Deproteinization rate, polysaccharide retention rate, antioxidant activities and inhibition $\alpha$-amylase effects were used as indicative mark to select suitable deproteinization method of CSPs. The crude CSPs was extracted by the hot water method. Results showed that TCA method had higher deproteinization rate and polysaccharide retention rate than that of Sevag method and $\mathrm{HCl}$ method, and the deproteinization optimum concentration of TCA was 4\%. Under the optimized conditions, the deproteinization rate and polysaccharide retention rate were $53.68 \%$ and $64.13 \%$ respectively. In terms of antioxidant and $\alpha$-amylase inhibitory effects, TCA-deproteinized CSPs (T-CSPs) had stronger activities, followed by Sevag-deproteinized CSPs (S-CSPs) and HCl-deproteinized CSPs (H-CSPs). Form a conclusion, TCA method was a good way to remove protein.
\end{abstract}

Keywords: Corn Silk, Polysaccharides, Deproteinization, Antioxidant Activities, $\alpha$-Amylase Inhibition Effect

\section{Introduction}

Corn silk (Stigma maydis) is the Stigma of Zea mays Line. In previous investigations of corn silk, it contains a variety of chemical constituents (He et al., 2012), such as volatile oil, saponins, alkaloids, flavonoids, polysaccharide and organic acids. It was reported that the extracts of corn silk also possessed extensive bioactivities including antihyperglycemic (Liu et al., 2002), antihypertensive, antioxidant (Chen et al., 2005) and immunomodulatory activity (Kim et al., 2004). As a natural polysaccharide, the polysaccharides from corn silk (CSPs) possessed significantly higher antioxidant and $\alpha$-amylase inhibitory abilities and might be used as a novel nutraceutical agent for human consumption (Maksimovic et al., 2003; Chen et al., 2013).

The existence of protein in polysaccharide fraction is a serious problem (a false conclusion may be led) during the study on characterization, physicochemical properties and biological activity of polysaccharides. Therefore, the proper characterization of these compounds requires deproteinization. And current researches had demonstrated that the pharmacological activities were also closely related to its richness of polysaccharides in the flesh (Wang et al., 2006). However, impurities, especially proteins, are co-precipitated with polysaccharides by ethanol, which poses a serious challenge for subsequent purification steps. It is necessary to find an effective method to remove proteins from crude polysaccharide extracts. For example, the free proteins of polysaccharides from Laminaria japonica are usually removed by the Sevage method, the deproteinization rate was $32.21 \%$ and the polysaccharide retention rate was $92.82 \%$ (Zha, 2012). Two different ways were employed to remove protein from polysaccharides in Echinops latifolius Tausch, results showed the protein removal rate of TCA and Sevag methods were $45.13 \%$ and $47.47 \%$, and the polysaccharide retention rate were $61.05 \%$ and $67.65 \%$, respectively (Yang et al., 2014). The deproteinization effects of above three methods were compared by the percentage of the deproteinization, polysaccharide loss and capacity of polysaccharide solution for scavenging DPPH free radical. The results showed that the effective order of these methods is $\mathrm{HCl}$ method, then TCA and finally Sevag method. As the $\mathrm{pH}$ value of polysaccharide solution is 2 as adjusted by $\mathrm{HCl}$, the results were the protein removal rate $88.9 \%$, the polysaccharide retention rate $85.2 \%$ and the capacity of polysaccharide solution scavenging DPPH 
free radical $45.6 \%$ (Dong et al., 2007). On the basis of guaranteeing the deproteinization rate and the retention rate of polysaccharides, the activities of polysaccharides should also be kept to the maximum extent.

The method used for deproteinization of CSPs should have both high deproteinization rate and polysaccharide retention rate and can't destroy the structure and activity of polysaccharides. Deproteinizing reagents should be safe and cheap. Therefore, in this study, the deproteinization conditions and effects of Sevag method, trichloroacetic acid (TCA) method or hydrochloric acid $(\mathrm{HCl})$ method were investigated. Deproteinization rate, polysaccharide retention rate, antioxidant activities (chelating ferrous ion ability, DPPH free radical scavenging ability, superoxide anions scavenging activity and Ferrous ion reducing power) and $\alpha$-amylase inhibitory activity were used as indicative mark. An efficient and convenient method for deproteinization of polysaccharides was obtained, which provides a basis for further development and utilization of CSPs.

\section{Materials and Methods}

\section{Materials}

Corn silk was obtained from the suburb of Jilin city, Jilin Province, China in 2017. Ascorbic acid (VC) were bought from Sinopharm Chemical Reagent Co. (Beijing). 1,1-Diphenyl-2-picrylhydrazyl (DPPH) and 2,2'-azinobis-(3-ethylbenzothiazoline-6-sulfonic acid) diammonium salt (ABTS) were purchased from Sigma-Aldrich (USA). Trichloro acetic acid, ferrous sulfate, potassium dihydrogen phosphate, sodium hydroxide, Ethylenediamine Tetraacetic Acid (EDTA), sulfuric acid, phenol and ethanol were purchased from Chemical Reagent Factory (Tianjin, China). All other reagents and chemicals used in the study were of analytical grade.

About $752 \mathrm{~N}$ UV visible spectrophotometry meter (Shanghai Chaojing science and Technology Co., Ltd.); HHV-6 digital thermostat water bath (Guohua Electrical Appliance Co., Ltd.); electronic balance (Shanghai Precision Scientific Instrument Co., Ltd.); pHs-3c digital pH meter (Shanghai Lida instrument factory); TGL-20M benchtop high speed refrigerated centrifuge (Hunan Xiangyi laboratory instrument Development Co., Ltd.).

\section{Methods}

\section{Extraction of the Crude CSPS}

The $100 \mathrm{~g}$ of corn silk was extracted with $3 \mathrm{~L}$ of water at $90^{\circ} \mathrm{C}$ for $1 \mathrm{~h}$ and then extracted for 3 times. The extraction solution was concentrated to $1 / 5$ of original volume, which was then precipitated by slowly adding ethanol (95\%, v/v) until the ethanol content dropped to $80 \%(\mathrm{v} / \mathrm{v})$ and then the solution was keeping the solution for $12 \mathrm{~h}$ at $4^{\circ} \mathrm{C}$. The precipitates obtained by centrifugation at $4000 \mathrm{rpm}$ for $10 \mathrm{~min}$ were lyophilized to obtain the crude CSPs (Cai et al., 2018).

Determination of Polysaccharide and Protein Content of CSPs

Glucose is the main component of CSPs (Chen et al., 2014), so the content of CSPs was determined by using glucose as the standard. Polysaccharide content of CSPs was determined by phenol sulfuric acid method (Georgiou et al., 2018; Cuesta et al., 2003). The sample solution $(0.5 \mathrm{~mL})$ and the phenol solution $(1.0$ $\mathrm{mL}$ ) were added to test tube, which were shocked. Then $3.5 \mathrm{ml}$ of concentrated sulfuric acid was added either directly against the liquid surface in 2 or $10 \mathrm{~s}$, or slowly down the side of the tube. The tubes were then shock for 5 $\mathrm{s}$ and incubated in water at $40^{\circ} \mathrm{C}$ for $30 \mathrm{~min}$. All tubes were allowed to cool down to room temperature before reading the absorbances at $490 \mathrm{~nm}$ using distilled water as blank in an Ultraviolet-Visible Spectrophotometer.

Protein content was determined by Coomassie brilliant blue G-250 staining with calf serum as standard (Xia et al., 2012). The sample solution (1.0 mL) and the Coomassie brilliant blue $\mathrm{G}-250$ solution $(5.0 \mathrm{~mL})$ were added to test tube and kept away from light for 5 $\min$. The absorption was measured at $595 \mathrm{~nm}$.

$$
\begin{gathered}
\text { The retention rate polysaccharide }(\%)=\frac{M_{1}}{M_{0}} \times 100 \% \\
\text { Deproteinized rate }(\%)=\frac{M_{2}-M_{3}}{M_{2}} \times 100 \%
\end{gathered}
$$

Where:

$M_{0}=$ Polysaccharide mass before deproteinized

$M_{1}=$ Polysaccharide mass after deproteinized

$M_{2}=$ Protein mass before deproteinized

$M_{3}=$ Protein mass after deproteinized

\section{Three Methods of Deproteinization of CSPs}

\section{Deproteinization by Sevag Method}

$50 \mathrm{~mL}$ of the crude CSPs solution $(2 \mathrm{mg} / \mathrm{mL})$ was transferred into a $250 \mathrm{~mL}$ conical flask and $20 \mathrm{~mL}$ of Sevag reagent (chloroform: $n$-buthanol, 5:1 (v/v)) was added. The mixed solution was continually stirred for $2 \mathrm{~min}$ and centrifuged at $4000 \mathrm{rpm}$ for $10 \mathrm{~min}$. As a result, the solution was divided into three layers, in order, CSPs solution after deproteinization, denatured protein and redundant Sevag reagent from top to bottom. The supernatant was repeatedly deproteinized with the same amount of Sevag reagent and the other two layers were recovered and disposed. After the last 
deproteinization step, the supernatant was collected and dried and Sevag-deproteinized CSPs (S-CSPs) were obtained (Xiong et al., 2017).

\section{Deproteinization by the TCA Method}

About $20 \mathrm{~mL}$ of the crude CSPs solution (2 $\mathrm{mg} / \mathrm{mL}$ ) was mixed with TCA solution $10 \mathrm{~mL}$, which the mass fractions were $2.0 \%, 4.0 \%, 6.0 \%, 8.0 \%$ and $10.0 \%(\mathrm{~m} / \mathrm{m})$ respectively. After sonication for 10 $\mathrm{min}$, the mixed solution was centrifuged at 4,000 rpm for $10 \mathrm{~min}$ and the supernatant was collected and dried to provide the TCA-deproteinized CSPs (TCSPs) (Huang et al., 2011).

\section{Deproteinization by the $\mathrm{HCl}$ Method}

About $20 \mathrm{~mL}$ of the crude CSPs solution (2 $\mathrm{mg} / \mathrm{mL})$ was adjusted to the designed $\mathrm{pH}(1,1.5,2.0$, $2.5,3.0)$ with $\mathrm{HCl}$ solution $(0.2 \mathrm{~mol} / \mathrm{L})$. After shaking, the mixed solution was centrifuged for $10 \mathrm{~min}$ at 4,000 rpm. The HCl-deproteinized CSPs (H-CSPs) was collected (Dong et al., 2007).

\section{Antioxidant Activity in Vitro of CSPs}

\section{Determination of Ferrous Ion Chelating Ability}

The test mixture included $1 \mathrm{~mL}$ sample solution $(0.2,0.4,0.6,0.8,1.0,2.0 \mathrm{mg} / \mathrm{mL}), 1 \mathrm{~mL}$ ferrous sulfate solution $(0.1 \mathrm{mmol} / \mathrm{L})$ and $1 \mathrm{~mL}$ Ferro Zine methanol solution $(0.25 \mathrm{mmol} / \mathrm{L})$ and the mixture was then shaken vigorously and left to stand in test tubes in the dark for $10 \mathrm{~min}$, the absorbance at $562 \mathrm{~nm}$ was then measured. Vitamin $\mathrm{C}(\mathrm{Vc})$ was used as a positive control (Qiao et al., 2009). The ferrous ion chelating ability was calculated according to the following equation:

$$
\text { Chelating rate }(\%)=\frac{A_{0}-A_{j}}{A_{0}} \times 100 \%
$$

$A_{0}=$ The absorbance of the blank control

$A_{\mathrm{i}}=$ The absorbance of the sample

\section{Determination of DPPH Free Radical Scavenging Ability}

About $100 \mu \mathrm{L}$ of sample solution (0.2, 0.4, 0.6, 0.8 and $1.0 \mathrm{mg} / \mathrm{mL}$ ) were mixed with DPPH-methanol solution $(100 \mu \mathrm{L}, 0.5 \mathrm{mM})$. The mixture was then shaken vigorously and left to stand in test tubes in the dark at room temperature for $30 \mathrm{~min}$, the absorbance at $517 \mathrm{~nm}$ was then measured (Liu et al., 2017). Vitamin C (Vc) was used as a positive control. The DPPH radical scavenging activity was calculated according to the following equation:

$$
\text { Thescavenging rate }(\%)=\left(1-\frac{A_{i}-A_{j}}{A_{0}}\right) \times 100 \%
$$

where, $A_{i}$ is the absorbance value of the DPPHethanol solution $(2 \mathrm{~mL})$ plus samples $(2 \mathrm{~mL})$ at different concentrations, $A_{\mathrm{j}}$ is the absorbance value of absolute ethanol $(2 \mathrm{~mL})$ plus samples $(2 \mathrm{~mL})$ at different concentrations, $A_{0}$ is the absorbance value of the DPPH-ethanol solution $(2 \mathrm{~mL})$ plus absolute ethanol $(2 \mathrm{~mL})$.

\section{Determination of Superoxide Anions Scavenging Activity}

About $200 \mu \mathrm{L}$ of $50 \mathrm{mmol} / \mathrm{L}$ Tris- $\mathrm{HCl}$ buffer

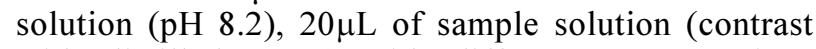
with distilled water) with different concentrations $(0.2,0.4,0.6,0.8$ and $1.0 \mathrm{mg} / \mathrm{mL})$ were added into the test tubes, respectively. The temperature was kept at $25^{\circ} \mathrm{C}$ for $20 \mathrm{~min}$ in the water bath. $20 \mu \mathrm{L}$ of the same prewarm pyrogallic acid solution $(0.03 \mathrm{~mol} / \mathrm{L})$ was added and reacted for $5 \mathrm{~min}$. The absorbances at $325 \mathrm{~nm}$ were quickly measured respectively. Tris- $\mathrm{HCl}$ buffer solution was used as a blank and Vc was as the control. Each group was done for 3 times (Song et al., 2010). The calculation formula of clearance rate (E) was as follows:

$$
\text { The scavenging rate }(\%)=\frac{A_{0}-A_{j}}{A_{0}} \times 100 \%
$$

$A_{0}=$ Was the absorbance value of the Tris- $\mathrm{HCl}$ buffer solution and the pyrogallic acid solution (the unsampled system)

$A_{i}=$ Was the absorbance value of sample

\section{Determination of Total Reduction Activity}

The test mixture included $2.5 \mathrm{~mL}$ of $0.2 \mathrm{~mol} / \mathrm{L}$ sodium phosphate buffer ( $\mathrm{pH} 6.6), 2.5 \mathrm{~mL}$ of $1 \%$ potassium hexacyanoferrate $\left(\mathrm{K}_{3} \mathrm{Fe}(\mathrm{CN})_{6}\right)$ solution $(\mathrm{w} / \mathrm{v})$ and $1.0 \mathrm{~mL}$ sample solution. The samples were tested using a series of concentrations $(0.2,0.4,0.6$, $0.8,1.0 \mathrm{mg} / \mathrm{mL})$. These mixtures were heated in water bath at $50^{\circ} \mathrm{C}$ for $20 \mathrm{~min}$. After cooling, $2.5 \mathrm{~mL}$ of trichloroacetic acid $(10 \%, \mathrm{w} / \mathrm{v})$ was added and the resulting mixture was centrifuged (3000 rpm, $10 \mathrm{~min}$ ). $2.5 \mathrm{~mL}$ the supernatant was collected and mixed with $2.5 \mathrm{~mL}$ deionized water and then the color was developed by adding $0.1 \%$ ferric chloride $(0.5 \mathrm{~mL})$. The absorbance at $700 \mathrm{~nm}$ was measured with spectrophotometer. Higher absorbance was indicative of greater reducing ability (Lan et al., 2018).

\section{Determination of $\alpha$-Amylase Inhibition Effects}

About $0.5 \mathrm{~mL}$ of sample solution $(0.8 \mathrm{mg} / \mathrm{mL})$ was added to $0.5 \mathrm{~mL}$ of $\alpha$-amylase before incubation at $37^{\circ} \mathrm{C}$ for $10 \mathrm{~min}$, followed by the addition of soluble starch solution $(1 \mathrm{~mL})$. After further incubating at $37^{\circ} \mathrm{C}$ for 15 $\mathrm{min}$, the reaction was terminated by adding $3 \mathrm{~mL}$ of hydrochloric acid solution $(2 \mathrm{~mol} / \mathrm{L})$. The reaction 
solution was diluted with $4 \mathrm{~mL}$ of distilled water and immediately added to a test tube containing $0.2 \mathrm{~mL}$ of dilute iodine solution and shaken. The absorbance was measured at $660 \mathrm{~nm}$ (Zhang et al., 2015). The percentage inhibition of $\alpha$-amylase was calculated as follows:

$$
\alpha \text {-Amylase inhibition rate }(\%)=\frac{A_{\text {sample }-A_{\text {backgrand }}}}{A_{\text {contral }}-A_{\text {background }}} \times 100 \%
$$

where, $A_{\text {control, }} A_{\text {sample }}$ and $A_{\text {background }}$ are defined as the absorbance at $100 \%$ enzyme activity (only for that solvent without the enzyme), a test sample (with the enzyme) and a blank (only for that solvent without the sample but with enzymes), respectively.

\section{Statistical Analysis}

The data are represented as mean \pm SD. The experimental data were statistically analyzed by ANOVA, $\mathrm{p}<0.05$ and $\mathrm{p}<0.01$ were considered statistically significant.

\section{Results}

\section{Polysaccharides and Protein Content of Crude CSPS}

The standard curve equation of glucose: $\mathrm{y}=$ $7.4352 \mathrm{x}+0.0071\left(\mathrm{R}^{2}=0.9998\right)$. The content of crude CSPs was $20.97 \%$. The standard curve equation of Bovine Serum Protein: $\mathrm{y}=5.4954 \mathrm{x}-0.2806\left(\mathrm{R}^{2}=\right.$ 0.9997). According to the formula, the protein content of crude CSPs was $10.78 \%$.

\section{Deproteinization Rates and Polysaccharide Retention Rate of Different Methods}

\section{Sevag Method}

Sevag is a kind of organic solvent, which affects the dielectric constant between protein and the medium, thereby changing the stability of the protein, so as to achieve the purpose of separating the protein from polysaccharide. As can be seen from Table 1, with the increase of the number of times, the polysaccharides retention rate decreased and the deproteinization rates increased. After two times deproteinizations, the deproteinization rate reached $43.14 \%$ and the polysaccharide retention rate reached $48.93 \%$, so it is too low.

\section{TCA Method}

Table 1 showed that with the increase of TCA concentration, the deproteinization rate increased first and then decreased and the polysaccharide retention rate decreased gradually. It might be that with the increase of TCA, the isoelectric point of protein was deviated and the polysaccharide was hydrolyzed by high concentration TCA, which resulted in the decrease of protein deproteinization rate and polysaccharide retention rate.
Table 1: Comparison of deproteinization rate (\%) and polysaccharide retention rate (\%) by different methods in removing proteins

\begin{tabular}{lcl}
\hline Method & $\begin{array}{l}\text { Deproteinized } \\
\text { rate }(\%)\end{array}$ & $\begin{array}{l}\text { Polysaccharide } \\
\text { retention rate (\%) }\end{array}$ \\
\hline $\begin{array}{l}\text { Sevag method to remove proteins } \\
1 \text { (times) }\end{array}$ & \\
2 (times) & $39.61 \pm 1.32$ & $60.61 \pm 2.39$ \\
TCA method to remove proteins & $48.93 \pm 1.89$ \\
$2.0 \%$ & $47.69 \pm 3.52$ & $68.56 \pm 3.19$ \\
$4.0 \%$ & $53.68 \pm 2.89^{*}$ & $64.13 \pm 2.28^{* *}$ \\
$6.0 \%$ & $46.64 \pm 3.45$ & $60.08 \pm 2.94$ \\
$8.0 \%$ & $38.66 \pm 2.32$ & $50.67 \pm 2.89$ \\
$10.0 \%$ & $35.42 \pm 1.96$ & $55.69 \pm 2.78$ \\
HCl method to remove proteins & \\
pH1.0 & $49.68 \pm 2.84$ & $48.42 \pm 2.89$ \\
pH 1.5 & $49.21 \pm 2.83$ & $50.36 \pm 2.84$ \\
pH 2.0 & $45.50 \pm 2.86^{\mathrm{ns}}$ & $58.06 \pm 2.72^{*}$ \\
pH 2.5 & $32.67 \pm 2.90$ & $59.18 \pm 2.38$ \\
pH 3.0 & $11.15 \pm 1.48$ & $61.27 \pm 1.36$ \\
\hline
\end{tabular}

Compared with Sevag method, TCA method and $\mathrm{HCl}$ method had significant differences in protein removal rate and polysaccharide retention rate. $(*: \mathrm{P}<0.05 ; * *: \mathrm{P}<0.01)$. Ns means that there was no significant difference.

The results showed that the optimum concentration of TCA was $4 \%$. The deproteinization rate was $53.68 \%$ and polysaccharide retention rate was $64.56 \%$.

\section{$\mathrm{HCl}$ Method}

As can be seen from Table 1, with the increase of $\mathrm{pH}$, the deproteinization rate decreases gradually, while the polysaccharide retention rate increases gradually and finally tends to balance. The result showed that 2 was the optimum $\mathrm{pH}$ value of $\mathrm{HCl}$ method for deproteinization.

The results were shown in Table 1, TCA method is more suitable for mass purification of CSPs considering the deproteinization rate, the retention rate of polysaccharides and the practicability of reagents.

\section{Antioxidant Activities of CSPs \\ Antioxidant Activities of Crude CSPs}

The ferrous ion chelating activity of crude CSPs and EDTA were presented in Fig. 1a. CSPs had a reducing ability to ferrous ions, the results indicated that with increasing concentration of polysaccharides, the ferrous ion chelating activity was also enhanced. The $\mathrm{IC}_{50}$ of crude CSPs and EDTA were $1.34 \mathrm{mg} / \mathrm{mL}$ and 0.03 $\mathrm{mg} / \mathrm{mL}$, respectively, so the reduction ability was weaker than EDTA.

DPPH radical rcavenging rctivity of crude CSPs and $\mathrm{Vc}$ were shown in Fig. 1b. The scavenging ability of DPPH free radicals was strong and the clearance rate was linear with the concentration of polysaccharide, the $\mathrm{IC}_{50}$ of crude CSPs and VC were $0.45 \mathrm{mg} / \mathrm{mL}$ and $0.05 \mathrm{mg} / \mathrm{mL}$, respectively. The results indicated that crude CSPs had a strong ability to remove DPPH free radicals, but the removal effect was less than Vc. 


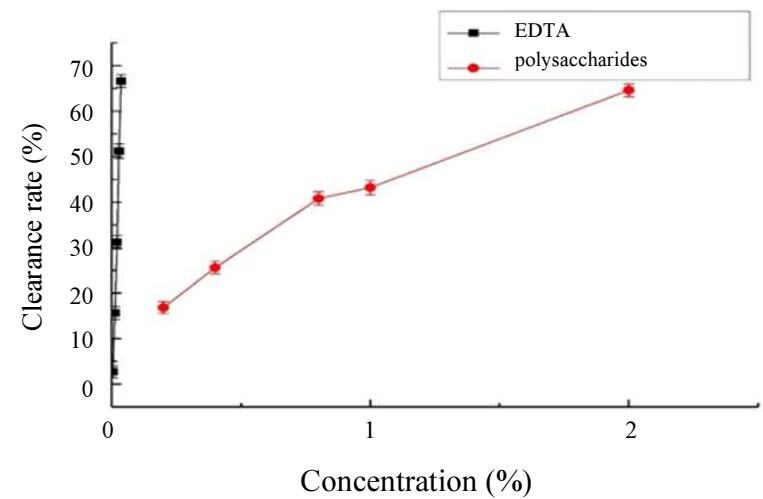

(a)

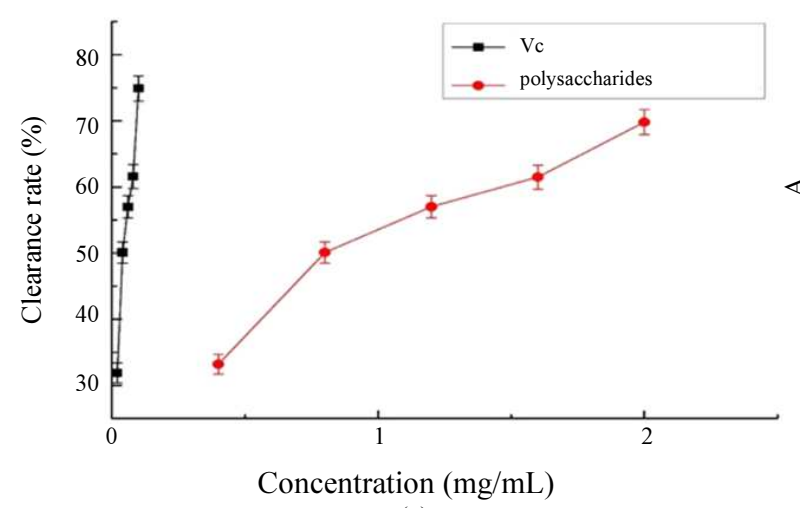

(c)

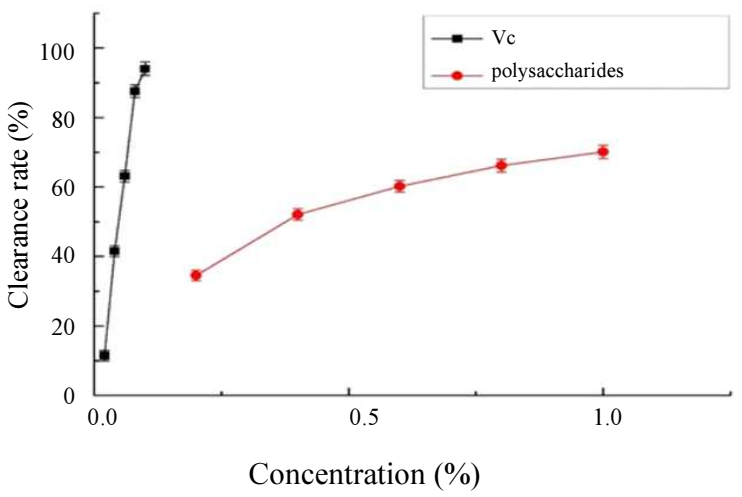

(b)

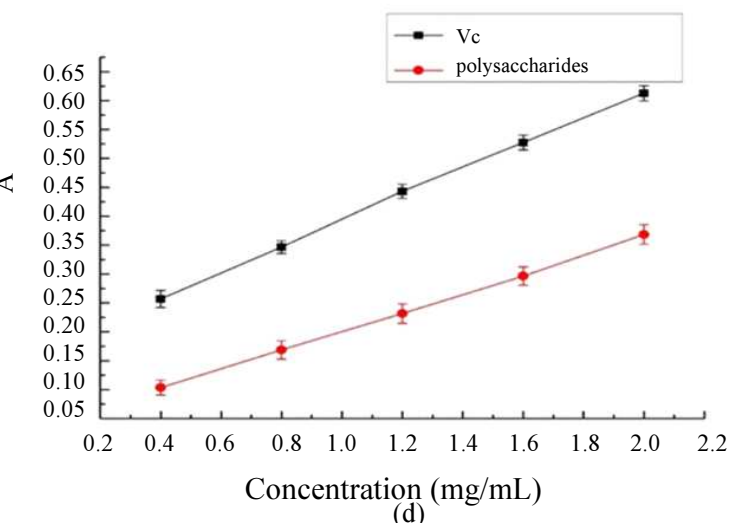

(d)

Fig. 1: Antioxidant activities of crude CSPs. Ferrous ion chelating ability (a) DPPH radical scavenging activity (b) Superoxide anion radical scavenging activity (c) Total reduction activity (d) Each value is the means \pm standard deviation (SD) of triplicate measurements

Table 2: Antioxidant Acticities and Inhibitory Effects on $\alpha$-amylase of polysaccharides after protein removal by different methods (Polysaccharides concentration was $0.8 \mathrm{mg} / \mathrm{mL}$ )

\begin{tabular}{|c|c|c|c|c|c|}
\hline Method & $\begin{array}{l}\text { Ferrousion } \\
\text { chelating } \\
\text { ability }(\%)\end{array}$ & $\begin{array}{l}\text { DPPH radical } \\
\text { scavenging } \\
\text { activity }(\%)\end{array}$ & $\begin{array}{l}\text { Superoxide anion } \\
\text { radical scavenging } \\
\text { activity }(\%)\end{array}$ & $\begin{array}{l}\text { Total reduction } \\
\text { activity }\end{array}$ & $\begin{array}{l}\text { Inhibitory Effects } \\
\text { on } \alpha \text {-amylase }(\%)\end{array}$ \\
\hline crude CSPs $(0.8 \mathrm{mg} / \mathrm{mL})$ & $40.80 \pm 1.67$ & $66.16 \pm 1.26$ & $50.12 \pm 1.43$ & $0.17 \pm 0.01$ & $71.94 \pm 1.24$ \\
\hline \multicolumn{6}{|l|}{ Sevag method (times) } \\
\hline 1 & $30.41 \pm 1.32$ & $77.30 \pm 1.15$ & $54.50 \pm 1.59$ & $0.12 \pm 0.01$ & $66.31 \pm 0.68$ \\
\hline 2 & $26.24 \pm 1.15^{--}$ & $68.04 \pm 1.13^{\mathrm{ns}}$ & $43.60 \pm 1.73^{-}$ & $0.11 \pm 0.01^{--}$ & $50.13 \pm 0.84^{---}$ \\
\hline \multicolumn{6}{|c|}{ TCA method (concentrations) } \\
\hline $2.0 \%$ & $60.62 \pm 1.36$ & $73.46 \pm 0.83$ & $66.50 \pm 1.43$ & $0.27 \pm 0.01$ & $70.08 \pm 0.94$ \\
\hline $4.0 \%$ & $55.09 \pm 1.54^{++++}$ & $75.91 \pm 0.96^{++++}$ & $64.04 \pm 1.50^{+++}$ & $0.29 \pm 0.01^{++++}$ & $68.01 \pm 0.73^{-}$ \\
\hline $6.0 \%$ & $49.29 \pm 149$ & $79.08 \pm 0.89$ & $58.99 \pm 1.63$ & $0.23 \pm 0.01$ & $60.92 \pm 0.68$ \\
\hline $8.0 \%$ & $47.57 \pm 1.59$ & $77.59 \pm 0.97$ & $47.60 \pm 1.54$ & $0.21 \pm 0.01$ & $59.04 \pm 0.87$ \\
\hline $10.0 \%$ & $46.83 \pm 1.25$ & $75.29 \pm 1.18$ & $50.20 \pm 1.39$ & $0.21 \pm 0.01$ & $57.98 \pm 0.67$ \\
\hline \multicolumn{6}{|l|}{$\mathrm{HCl}$ method $(\mathrm{pH})$} \\
\hline 1.0 & $21.45 \pm 1.67$ & $77.05 \pm 0.94$ & $33.10 \pm 1.49$ & $0.16 \pm 0.01$ & $47.84 \pm 0.56$ \\
\hline 1.5 & $32.63 \pm 1.49$ & $68.14 \pm 0.85$ & $20.00 \pm 1.52$ & $0.11 \pm 0.01$ & $55.07 \pm 0.62$ \\
\hline 2.0 & $33.04 \pm 1.57^{--}$ & $62.04 \pm 0.79^{-}$ & $17.11 \pm 1.73^{-}$ & $0.10 \pm 0.01^{--}$ & $60.42 \pm 0.91^{---}$ \\
\hline 2.5 & $22.76 \pm 1.38$ & $70.25 \pm 0.94$ & $12.64 \pm 1.63$ & $0.09 \pm 0.01$ & $62.8 \pm 0.58$ \\
\hline 3.0 & $16.48 \pm 1.63$ & $74.36 \pm 1.17$ & $38.83 \pm 1.39$ & $0.10 \pm 0.01$ & $63.33 \pm 0.87$ \\
\hline
\end{tabular}

Compared with crude CSPs, there were significant differences in antioxidant activities and $\alpha$-amylase inhibitory activities of SCSPs, T-CSPs and H-CSPs under the optimal conditions of the three methods. "+" represented positive significant difference and "-"

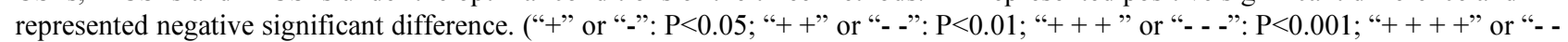
- .": $\mathrm{P}<0.0001)$. Ns means that there was no significant difference. 
Superoxide Radical Scavenging Activity of the crude CSPs and Vc were shown in Fig. 1c. The crude CSPs had strong ability to scavenge superoxide anion radicals and the clearance rate was dose-dependent with the concentration of polysaccharide. The $\mathrm{IC}_{50}$ of crude CSPs and Vc were $1.00 \mathrm{mg} / \mathrm{mL}$ and $0.50 \mathrm{mg} / \mathrm{mL}$, respectively. The results indicated that the crude CSPs has a strong ability to remove superoxide anion free radicals, but the removal effect is less than Vc.

Total antioxidant capacity of the crude CSPs and Vc were shown in Fig. 1d. The crude CSPs had a certain ability to restore. The reduction abilities of crude CSPs and Vc were dose-dependent and increased with the increase of concentration, but the reducing ability of polysaccharide was less than that of $\mathrm{Vc}$.

\section{Antioxidant Activities of CSPs After Deproteinized}

Results as shown in Table 2, when the concentration of polysaccharide was $0.8 \mathrm{mg} / \mathrm{mL}$, the antioxidant activities of T-CSPs was stronger than those of crude CSPs, S-CSPs and H-CSPs. The antioxidant activity of T-CSPs decreased with the increase of TCA concentration, which might be that too much TCA would destroy the structure of polysaccharides. The low deproteinization rate and polysaccharide retention rate of S-CSPs resulted in the lower purity of S-CSPs than that of T-CSPs, so the antioxidant activities of SCSPs was lower than that of T-CSPs. The structure of $\mathrm{H}$-CSPs might be severely damaged by $\mathrm{HCl}$, resulting in the decrease of their activities. Compared with the antioxidant activities of CSPs, the antioxidant activiies of T-CSPs was improved, which indicated that TCA was one of the effective ways to improve the purity and antioxidant activity of polysaccharides.

\section{Amylase Inhibitory Activities of CSPs}

From Table 2 , it could be seen that the $\alpha$-amylase inhibitory activities of S-CSPs decreased with the increase of deproteinization times. The $\alpha$-amylase inhibitory activity of T-CSPs reduced with the increase of TCA concentration, it might be that excessive TCA destroyed the structure of CSPs and leaded to the decrease of their activity. The $\alpha$-amylase inhibitory activity of H-CSPs strenghten with the increase of $\mathrm{pH}$. The amylase inhibitory activity of $\mathrm{H}-$ CSPs was lower than that of crude CSPs, it might be that the structure of polysaccharides had changed or that proteins with $\alpha$-amylase inhibitory activity had been removed. However, compared with crude CSPs, when the concentration of TCA was $4 \%$, the $\alpha$ amylase inhibitory activity of T-CSPs decreased less than those of S-CSPs and H-CSPs. The results showed that the activity of CSPs could be preserved when $4 \%$ TCA was used for deproteinization. The inhibitory activity of amylase of T-CSPs was stronger than those of S-CSPs and H-CSPs.

\section{Discussion}

The most typical depropeinization method was Sevag method, however, it involved excessive consumption of chloroform and $n$-buthanol, which resulted in massive amount of organic toxicities. Furthermore, there was a dramatic loss of polysaccharide after several times Sevag treatment (Xiong et al., 2015). Therefore, Sevag method is not suitable for mass purification of CSPs. The results of deproteinization by $\mathrm{HCl}$ method showed that with the increase of $\mathrm{pH}$ value, the concentration of $\mathrm{HCl}$ decreased, which could not destroy the protein sufficiently, leading to the decrease of protein removal rate. However, the hydrolysis of CSPs could decrease, resulting in a corresponding increase in the retention rate of CSPs, but $\mathrm{HCl}$ destroys the structure of CSPs, resulting in a sharp decrease in antioxidant activity and $\alpha$-amylase inhibition effect of $\mathrm{H}$-CSPs. So $\mathrm{HCl}$ method is not suitable for deproteinization of CSPs (Qiang et al., 2010). The principle of TCA method is that the protein cation can bind the TCA to form an insoluble salt for precipitation at $\mathrm{pH}<\mathrm{pI}$ (isoelectric point). The strong acidity of TCA could cause the degradation of CSPs and consequently the loss of CSPs, so the concentration of TCA should not be too high (Teng et al., 2013). The antioxidant activity of TCSPs was stronger than that of crude CSPs and it's $\alpha$ amylase inhibition effect was also higher than those of $\mathrm{S}-\mathrm{CSP}$ a and H-CSPs. The results showed that the antioxidant activity of CSPs was improved after deproteinization by TCA method. According to the deproteinization rate, polysaccharide retention rate, antioxidant activity and $\alpha$-amylase inhibition effect. Compared with the other two methods, TCA method is an efficient and inexpensive deproteinization method, which was suitable for mass purification of CSPs.

\section{Conclusion}

The results demonstrated that the TCA method offers higher deproteinization rate and polysaccharides retention rate than the Sevag method and $\mathrm{HCl}$ method and the antioxidant and $\alpha$-amylase inhibitory effects of T-CSPs were stronger than those of S-CSPs and H-CSPs. T-CSPs had stronger the antioxidant activity than that of crude CSPs and the $\alpha$ amylase inhibitory activity of T-CSPs was close to that of crude CSPs. Therefore, TCA method was suitable for mass purification of CSPs. However, further studies on the possible loss of glycoproteins, deproteinization efficiency, effect on the biological activity of polysaccharides and mechanism of protein removal, should be carried out in the near future. 


\section{Acknowledgments}

Funding: This work was supported by the Technology Bureau of Jilin City [grant No. 201851869] and Jilin Province Development and Reform Commission [grant No. 2019C045-4].

\section{Author's Contributions}

Yaping Li: Antioxidant activity and $\alpha$-amylase inhibitory activity of CSPs before and after deproteinization and composing of thesis

Songbiao Shi: The research on the deproteinization of CSPs.

Xiudong Yang: The revision and proofreading of the thesis.

Hongli Zhou: The design and guidance of research.

\section{Ethics}

This article is original and contains unpublished material. The corresponding author confirms that all of the other authors have read and approved the manuscript and no ethical issues involved.

\section{References}

Chen, S.H., H.X. Chen, J.G. Tian, Y.W. Wang and L.S. Xing et al., 2013. Chemical modification, antioxidant and $\alpha$-amylase inhibitory activities of corn silk polysaccharides. Carbohydrate Polymers, 98: 428-437. DOI: 10.1016/j.carbpol.2013.06.011

Cai, L., S. Zou, D. Liang and L. Luan, 2018. Structural characterization, antioxidant and hepatoprotective activities of polysaccharides from Sophorae tonkinensis Radix. Carbohydrate Polymers, 184: 354-365.

DOI: 10.1016/j.carbpol.2017.12.083

Cuesta, G., N. Suarez, M.I. Bessio, F. Ferreira and H. Massaldi, 2003. Quantitative determination of pneumococcal capsular polysaccharide serotype 14 using a modification of phenol-sulfuric acid method. J. Microbiol. Methods, 52: 69-73.

DOI: 10.1016/s0167-7012(02)00151-3

Chen, S.H., H.X. Chen, J.G. Tian, J. Wang and Y.W. Wang et al., 2014. Enzymolysis-ultrasonic assisted extraction, chemical characteristics and bioactivities of polysaccharides from corn silk. Carbohydrate Polymers, 101: 332-341.

DOI: 10.1016/j.carbpol.2013.09.046

Chen, H., M. Zhang and B. Xie, 2005. Components and antioxidant activity of polysaccharide conjugate from green tea. Food Chem., 90: 17-21.

DOI: $10.1016 /$ j.foodchem.2004.03.001
Dong, Y., Y.F. Zhang and Y.H. Sun, 2007. Comparison of deproteinization methods for milk thistle crude polysaccharide. Food Sci., 28: 82-84.

DOI: $10.3321 /$ j.issn:1002-6630.2007.12.014

Georgiou, C.D., D. Zisimopoulos, V. Argyropoulou, E. Kalaitzopoulou and G. Salachas et al., 2018. Protein and cell wall polysaccharide carbonyl determination by a neutral $\mathrm{pH}$ 2,4-dinitrophenylhydrazine-based photometric assay. Redox Bio., 17: 128-142.

DOI: 10.1016/j.redox.2018.04.010

He, YT., H.N. Gao, Y.X. Xu, X.M. Pan and J.R. Li, 2012. Chemical analysis and antioxidant activities in vitro of polysaccharide extracted from corn silk. Advanced Materials Res., 535-537: 2335-2339.

DOI: 10.4028/www.scientific.net/amr.535-537.2335

Huang, G., Y. Chen and X. Wang, 2011. Extraction and deproteinization of pumpkin polysaccharide. Int. J. Food Sci. Nutrit., 62: 568-571. DOI: $10.3109 / 09637486.2011 .560566$

Kim, K.A., S.K. Choi and H.S. Choi, 2004. Corn silk induces nitric oxide synthase in murine macrophages. Experimental Molecular Medicine, 36: 545-550. DOI: $10.1038 / \mathrm{emm} .2004 .69$

Lan, Z., Y. Hu, D. Xiaoyu, T. Tanga, Y. Shenb and B. $\mathrm{Hu}$ et al., 2018. Characterization and antioxidant activities of polysaccharides from thirteen boletus mushrooms. Int. J. Bio. Macromolecules, 113: 1-7. DOI: 10.1016/j.ijbiomac.2018.02.084

Liu, H., T. Xia and Q. Wang, 2002. Experimental study on therapeutic mechanism of kaiyu qingwei granules in reducing blood sugar. Chinese J. Experimental Traditional Med. Formulae, 5: 31-33. DOI: 10.13422/j.cnki.syfjx.2002.05.015

Liu, Q, X. Ge, L. Chen, D. Cheng and R. Shao et al., 2017. Purification and analysis of the composition and antioxidant activity of polysaccharides from Helicteres angustifolia L. Int. J. Bio. Macromolecules, 107: 2262-2268. DOI: $10.1016 /$ j.ijbiomac.2017.10.095

Maksimovic, Z.A. and N. Kovacevic, 2003. Preliminary assay on the antioxidative activity of Maydis stigma extracts. Fitoterapia, 74: 144-147.

Qiao, D, C. Kea, B. Hua, J. Luoa and H. Yea et al., 2009. Antioxidant activities of polysaccharides from Hyriopsis cumingii. Carbohydrate Polymers, 78: 199204. DOI: $10.1016 /$ j.carbpol.2009.03.018

Qiang L.I., A.L. Ding, W. Zheng and J. Sun, 2010. Effect of deproteinization methods on the total antioxidant ability of polysaccharide from Valeriana jatamansi. Chinese J. Experimental Traditional Medical Formulae, 16: 18-21.

DOI: 10.13422/j.cnki.syfjx.2010.08.017 
Song, H., Q. Zhang, Z. Zhang and J. Wang, 2010. In vitro antioxidant activity of polysaccharides extracted from Bryopsis plumosa. Carbohydrate Polymers, 80: 1057-1061. DOI: 10.1016/j.carbpol.2010.01.024

Teng, L.P., H. Zeng, H.B. Wang, Q.Y. Meng and Z.B. Zhou, 2013. Study on the deproteinization technology of crude polysaccharide from helvella leucopus pers. J. Henan Agri. Sci., 42: 138-137. DOI: 10.15933/j.cnki.1004-3268.2013.09.008

Wang, J., Y. Yao, J.P. Zhang, J.H. Liu and B.H. Jiao et al., 2006. Preparation and biological activity of polysaccharides from Ostrea rivularis in the East China Sea. J. Med. Postgraduates, 3: 217-220. DOI: $10.16571 /$ j.cnki.1008-8199.2006.03.008

Xia, L., Z. Rui, L.Z. Hong and D.H. Wu, 2012. Deproteinization of Polysaccharide from the Stigma Maydis by Sevag Method. Advanced Materials Res. 340: 416-420.

DOI: $10.4028 /$ www.scientific.net/amr.340

Xiong, Q., S. Huangab, J. Chend, B. Wange and L. HefLei et al., 2017. A novel green method for deproteinization of polysaccharide from Cipangopaludina Chinensis by freeze-thaw treatment. J. Cleaner Product., 142: 3409-3418.

DOI: $10.1016 /$ j.jclepro.2016.10.125
Xiong, Q., Y. Jing, X. Li, S. Zheng and X. Wang et al., 2015. Characterization and bioactivities of a novel purified polysaccharide from Endothelium corneum gigeriae Galli. Int. J. Bio. Macromolecules, 78: 324-332.

DOI: 10.1016/j.ijbiomac.2015.04.015

Yang, B., Y. Ying, W. Xue-Fei, H. Yan-Qing and F. Lin et al., 2014. Optimization of deproteinized process from Echinops latifolius Tausch polysaccharide by response surface methodology. Sci. Technol. Food Industry, 35: 287-291. DOI: $10.13386 /$ j.issn1002-0306.2014.10.055

Zha, X.Q., 2012. Polysaccharides in Laminaria japonica (LP): Extraction, physicochemical properties and their hypolipidemic activities in diet-induced mouse model of atherosclerosis. Food Chem., 134: 244-252. DOI: 10.1016/j.foodchem.2012.02.129

Zhang, S.Y., J.Q. Zhou, L.I. Shao-Hua, Y. Sun and Y.J. Gao, 2015. Effect of okra polysaccharide on $\alpha$ amylase inhibition and its spectral analysis. Sci. Technol. Food Ind., 36: 101-104.

DOI: 10.13386/j.issn1002-0306.2015.04.013 